\title{
Associate Degree
}

National Cancer Institute

\section{Source}

National Cancer Institute. Associate Degree. NCI Thesaurus. Code C71340.

A degree granted by a two-year college on successful completion of the underg raduates course of studies. 